\title{
Mutu Petik Teh (Camellia sinensis (L.) O. Kuntze) di Kebun Bedakah, Wonosobo, Jawa Tengah
}

The Quality of the Pick's Tea (Camellia sinensis (L.) O. Kuntze) in the Bedakah Plantation, Wonosobo, Central Java

\section{Synthia Dewi dan Purwono*}

Departemen Agronomi dan Hortikultura, Fakultas Pertanian, Institut Pertanian Bogor (Bogor Agricultural University), J1. Meranti, Kampus IPB Darmaga, Bogor 16680, Indonesia

Telp.\& Faks.62-251-8629353 e-mail agrohort@apps.ipb.ac.id

*Penulis Korespondensi : puripb@gmail.com

Disetujui : 21 Mei 2018 / Published Online September 2019

\begin{abstract}
The aims of this research are to find out the quality of tea plantation in the garden. This research was conducted for 4 months from January to June 2018 at Bedakah Plantation, Wonosobo, Central Java. Observation of the object of garden activity should also be done mainly on the aspect of picking and production. The analysis of picking in May 2018 with medium shoot composition of $23.83 \%$ did not meet the established standard of 50\%. Analysis of shoots in April had met the requirements for processing seen from the average of proper shoots is $51.44 \%$. Result from the analysis found that shoots of tea plants in JanuaryApril 2018 with an average of $48.78 \%$ of shoots eligible processing (MS) had not met the standard that was $50 \%$.
\end{abstract}

Keyword: picked tea quality, picking anaysis, tea plant

\begin{abstract}
ABSTRAK
Penelitian ini bertujuan untuk mengetahui mutu petik tanaman teh yang dilaksanakan di kebun. Kegiatan penelitian ini dilaksanakan selama 4 bulan mulai dari bulan Januari sampai Juni 2018 di Kebun Bedakah, Wonosobo, Jawa Tengah. Pengamatan terhadap objek kegiatan kebun juga harus dilakukan terutama pada aspek pemetikan dan produksi. Analisis petik pada bulan Mei 2018 dengan komposisi pucuk medium sebesar $23.83 \%$ belum memenuhi standar yang ditetapkan yaitu $50 \%$. Analisis pucuk pada bulan April sudah memenuhi syarat pengolahan dilihat dari rata-rata yaitu $51.44 \%$. Analisis pucuk pada bulan Januari-April 2018 dengan rata-rata sebesar $48.78 \%$ pucuk memenuhi syarat pengolahan (MS) belum memenuhi standar yaitu $50 \%$.
\end{abstract}

Kata kunci: analisis petik, mutu petik teh, tanaman teh 


\section{PENDAHULUAN}

Perkembangan areal tanaman teh di Indonesia terus menurun sejak Tahun 2000, sehingga pada Tahun 2015 hanya tersisa seluas 118441 ha dengan sebagian besar (44.58\%) diusahakan oleh perkebunan rakyat sedangkan sisanya berupa perkebunan besar negara $(31.47 \%)$ dan perkebunan besar swasta (23.94\%). Indonesia merupakan Negara produsen teh pada urutan ke lima di dunia setelah India, Cina, Sri Lanka, dan Kenya. Pada tahun 2015 total produksi teh Indonesia mencapai 154598 ton atau 5.7 persen dari total produksi the dunia yang mencapai 5304500 ton dengan produktivitas $1689 \mathrm{~kg} / \mathrm{ha}$ (International Tea Committee / ITC, 2015)

Teh merupakan salah satu komoditas hasil perkebunan yang mempunyai peran cukup penting dalam kegiatan perekonomian di Indonesia. Volume ekspor teh di Indonesia berfluktuasi setiap tahunnya. Volume ekspor teh pada tahun 2015 mengalami penurunan sebesar $25.59 \%$ dengan total volume ekspor sebesar 67 314 ton dan total nilai sebesar USD 132501 (Ditjenbun, 2015). Penurunan volume ekspor disebabkan adanya berbagai permasalahan yaitu teknik budidaya dan pengolahan yang tidak tepat sehingga menurunkan kuantitas dan kualitas teh yang belum memenuhi standar internasional. Peningkatan kualitas atau mutu teh dilakukan untuk menghasilkan pucuk teh bermutu tinggi (Supit, 2009).

Menurunnya agroindustri teh Indonesia kini terjadi karena belum dapat diatasinya masalahmasalah yang dihadapi oleh teh Indonesia, seperti rendahnya produktivitas tanaman karena dominannya tanaman teh rakyat yang belum menggunakan benih unggul, terbatasnya penguasaan teknologi pengolahan produk dan belum mampunya petani mengikuti teknologi yang telah direkomendasikan (Good Agriculture Practice / GAP dan Good Manufacture Process / $G M P)$ serta standar kualitas produk sebagaimana disyaratkan oleh ISO (Kementerian Pertanian, 2014).

Pucuk teh yang bermutu tinggi merupakan bahan baku untuk menghasilkan teh yang bermutu tinggi. Teh bermutu tinggi dan dengan pengelohan yang benar serta penggunaan mesinmesin yang memadai. Upaya yang dapat dilakuan untuk meningkatkan produksi dan mutu teh salah satunya adalah dengan memperbaiki sistem pemetikan yang lebih efisien sehingga dapat mencapai hasil yang maksimal (Nazaruddin dan Paimin, 1993). Pemetikan berkaitan erat dengan pertumbuhan tunas. Kecepatan pertumbuhan tunas mempengaruhi oleh daun-daun yang tertinggal perdu yang biasa disebut daun pemeliharaan.

Kecepatan pertumbuhan tunas akan mempengaruhi beberapa aspek pemetikan, yaitu jenis pemetikan, giliran petik, pengaturan areal petik, dan tenaga pemetik, serta pelaksaan pemetikan (Setyamidjaja, 2000).

Pengelolaan dalam pemetikan merupakan hal penting dalam tercapainya mutu teh yang baik secara kuantitas maupun kualitas. Baik tidaknya pengelolaan pemetikan di suatu perkebunan teh dapat dilihat melalui beberapa indikator, salah satunya melalui tebal daun pemeliharaan. Produksi tanaman menunjukkan penurunan saat tanaman berumur tiga tahun setelah pangkas yang dipengaruhi oleh jenis teh yang ditanam (Qibtiyah, 2009).

\section{METODE}

Kegiatan ini dilaksanakan di Kebun Bedakah, Wonosobo, Jawa Tengah. Kegiatan ini dilaksanakan selama 4 bulan mulai dari bulan Januari sampai Juni 2018. Data yang akan diamati dan dikumpulkan pada kegiatan terdiri dari data primer dan data sekunder. Data primer diperoleh dari kegiatan dan diskusi yang telah dilaksanakan di lapangan. Data sekunder diperoleh dari kantor administrasi kebun yang terdiri dari keadaan umum kebun (letak geografis kebun, keadaan iklim, jenis tanah, topografi lahan, dan produksi tanaman), data analisis pucuk, manajemen dan organisasi perusahaan. Pengamatan dilakukan dengan peubah data analisis petik dan analisis pucuk. Data analasis petik didapatkan dengan cara mengambil sampel hasil petikan secara acak dari setiap blok dengan tiga kali ulangan sedangkan data analisis pucuk diperoleh dari kantor administratif kebun.

Gilir dan hanca petik diperoleh dari kantor administratif kebun. Data kapasitas petik diperoleh dari kantor administratif, sedangkan kapasitas pemetik yang diatas 40 dan dibawah 40 tahun data diambil dari buku klat pemetik. Kebutuhan tenaga pemetik diperoleh dari kantor administratif kebun. Produktivitas berdasarkan umur setelah pangkas didapatkan dari kantor administratif kebun. Analisis data dilakukan secara kualitatif dan kuantitatif. Analisis kualitatif berupa penjabaran mengenai seluruh data dan informasi yang diperoleh di lapangan sedangkan analisis kuantitatif digunakan dalam pengolahan data berupa perhitungan secara matematis meliputi rata-rata dan persentase hasil, dan uji tstudent. 


\section{HASIL DAN PEMBAHASAN}

\section{Analisis Petik}

Analisis petik merupakan suatu kegiatan pemisahan pucuk hasil pemetikan yang didasarkan pada jenis pucuk atau rumus petik yang dihasilkan dari pemetikan yang telah dilakukan dan dinyatakan dalam persen. Tujuan dari analisis petik yaitu untuk mengetahui keterampilan pemetik, siklus petik, dan untuk menilai kondisi kesehatan tanaman.

Hasil dari petikan halus memiliki rata-rata $2 \%$, petikan medium $23.83 \%$, petikan kasar $42.25 \%$, dan petikan rusak $31.67 \%$. Standar analisis yang ditetapkan di Kebun Bedakah adalah $50 \%$ petikan tidak rusak. Hasil analisis petik disajikan pada Tabel 1 .

Berdasarkan Tabel 1 dapat dilihat bahwa hasil beberapa blok menunjukkan analisis petik berbeda nyata dari enam blok yang diamati. Petikan halus pada blok Mandala sangat berbeda nyata terhadap blok Muria. Petikan medium pada Rinjani berbeda nyata dengan blok Argopuro. Petikan kasar pada blok Bismo dan blok Mandala memberikan hasil yang berbeda nyata, namun dibandingkan pada blok Rinjani dan blok Muria tidak berbeda nyata. Petikan rusak pada blok Muria berbeda nyata terhadap Kembang.

Faktor yang mempengaruhi tinggi dan rendahnya petikan medium yaitu kondisi tanaman, cara pemetikan, dan gilir petik. Standar petikan medium yang telah di tetapkan di Kebun Bedakah yaitu menyertakan dua atau tiga daun beserta pucuk, namun beberapa pemetik seringkali memetik hingga daun kepel. Hal tersebut terjadi karena pemetik lebih mementingkan kuantitas yang ingin dicapai dari kualitas teh yang diolah. Nilai persentase pucuk rusak yang tinggi disebabkan juga oleh penanganan pucuk yang kurang baik dan cara pemetikan yang kurang benar.

Tabel 1. Hasil analisis pemetikan pucuk menggunakan gunting di Kebun Bedakah bulan Mei 2018

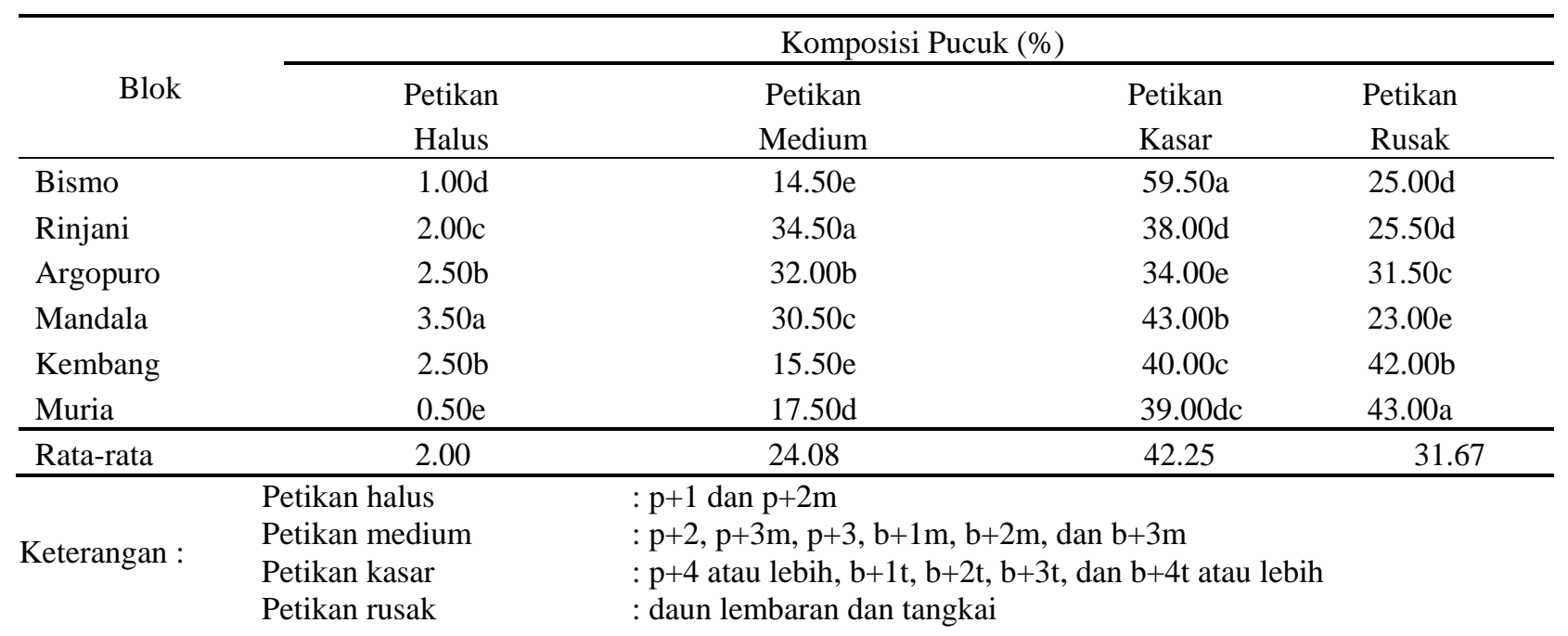

Tabel 2. Hasil analisis pucuk pemetikan menggunakan gunting di Kebun Bedakah bulan Januari-April 2017

\begin{tabular}{|c|c|c|c|c|c|c|c|c|}
\hline \multicolumn{9}{|c|}{ Analisi pucuk (\%) } \\
\hline \multirow{2}{*}{ Blok } & \multicolumn{2}{|c|}{ Januari } & \multicolumn{2}{|c|}{ Februari } & \multicolumn{2}{|c|}{ Maret } & \multicolumn{2}{|c|}{ April } \\
\hline & MS & TMS & MS & TMS & MS & TMS & MS & TMS \\
\hline Bismo & 50.08 & 49.92 & 46.74 & 53.26 & 46.92 & 53.08 & 50.10 & 49.90 \\
\hline Rinjani & 48.76 & 51.24 & 47.74 & 52.26 & 50.14 & 49.86 & 52.04 & 47.96 \\
\hline Mandala & 47.75 & 52.25 & 42.83 & 57.17 & 51.47 & 48.53 & 52.35 & 47.65 \\
\hline Argopuro & 46.40 & 53.60 & 45.96 & 54.04 & 51.31 & 48.69 & 50.62 & 49.38 \\
\hline Kembang & 45.86 & 54.14 & 45.90 & 54.10 & 50.72 & 49.28 & 51.15 & 48.85 \\
\hline Muria & 49.13 & 50.87 & 43.39 & 56.61 & 51.06 & 48.94 & 52.35 & 47.65 \\
\hline Rata-rata & 47.97 & 52.00 & 45.43 & 54.57 & 50.27 & 49.73 & 51.44 & 48.57 \\
\hline
\end{tabular}

Sumber : Laporan produksi Kebun Bedakah tahun 2018

Keterangan : $\quad$ Pucuk memenuhi syarat (MS) : p+1, p+2, p+3, b+1m, b+2m, b+3m

Pucuk tidak memenuhi syarat (TMS) : p+4 atau lebih, b+(1-5)t, lembaran, daun+tangkai tua 


\section{Analisis Pucuk}

Analisis pucuk yaitu pemisahan pucuk berdasarkan daun muda yang memenuhi syarat olah (MS) dan daun tua yang tidak memenuhi syarat olah (TMS). Analisis pucuk ini dilakukan sebelum melakukan proses pengolahan dimulai. Tujuan dari analisis pucuk ini yaitu untuk mengetahui petikan, mutu pucuk yang dihasilkan, menilai pucuk yang akan diolah, serta menentukan upah petik untuk setiap pemetik. Analisis menunjukkan rata-rata untuk daun muda yang memenuhi syarat (MS) 48.78\%, sedangkan daun tua yang tidak memenuhi syarat (TMS) yaitu $51.22 \%$. Standar analisis pucuk yang ditetapkan yaitu 50\% pucuk memenuhi syarat. Hasil analisis pucuk bulan Januari-April 2018 disajikan pada Tabel 2.

Analisis pucuk berfungsi untuk menilai kondisi pucuk yang akan diolah, menetukan harga pucuk, dan memperkirakan persentase mutu teh jadi yang akan dihasilkan. Tingginya pucuk yang tidak memenuhi syarat yaitu dapat disebabkan oleh pemetikan yang tidak sesuai, gilir petik yang terlalu panjang, serangan hama dan penyakit, serta perlakuan pucuk hasil petikan dari kebun ke pabrik.

\section{Gilir Petik dan Hanca Petik}

Gilir petik yang tepat akan menetukan produksi dan produktivitas. Semakin tua umur pangkas maka akan semakin lambat pertumbuhan pucuk sehingga semakin panjang gilir petik. Kecepatan pertumbuhan tanaman teh pada daratan tinggi akan lebih lambat dari tanaman teh yang berada pada dataran renda, hal ini dikarenakan intensitas cahaya yang kurang, suhu yang rendah dan kelembaban yang tinggi. Kelembaban yang tinggi dapat memacu pertumbuhan gulma menjadi semakin tinggi, sehingga akan terjadi persaingan unsur hara yang lebih tinggi (PPTK, 2010).
Gilir petik di Kebun Bedakah berdasarkan pengamatan terlihat pada blok yang terletak pada dataran tinggi (>1 $400 \mathrm{mdpl}$ ) memiliki gilir petik lebih panjang, yaitu antara 70-80 hari sedangkan pada blok yang terletak pada dataran rendah ( $<1400 \mathrm{mdpl}$ ) lebih pendek, yaitu antara 50-70 hari. Hasil gilir petik pada Kebun Bedakah berkisar 49-73 hari.

Hanca petik yaitu luas areal yang harus selesai dipetik pada satu hari. Luas areal petik diatur berdasarkan kapasitas rata-rata pemetik, blok kebun, dan gilir petik. Semakin pendek gilir petik maka hanca petik akan semakin luas dan begitu juga sebaliknya. (PPTK, 2006). Pengaturan hanca petik dilakukan dengan pertimbangan keseragaman pucuk yang dihasilkan setiap hari. Semakin baik kondisi pucuk dilapangan maka hanca petik akan semakin besar. Topografi kebun juga mempengaruhi besarnya hanca petik pada kegiatan pemetikan. Hanca petik pada setiap blok ditentukan oleh pembimbing petik. Nilai rata-rata hanca per pemetik pada Kebun Bedakah sebesar 0.031 ha hari ${ }^{-1}$.

\section{Kapasitas Petik}

Kapasitas pemetik yaitu banyaknya pucuk yang dipetik oleh pemetik dalam satu hari. Standar kapasitas pemetik (basic yield) yang ditetapkan pada Kebun Bedakah dalam kegiatan pemetikan dengan menggunakan gunting petik adalah sebesar $100 \mathrm{~kg}$. Kapasitas pemetik pada bulan Januari sampai dengan bulan April 2018 memiliki rata-rata $98.78 \mathrm{~kg}$ per pemetik. Penurunan nilai rata-rata pada bulan Maret dikarenakan oleh kondisi tanaman yang kurang sehat dan kondisi cuaca yang tidak menentu. Kapasitas pemetik pada Kebun Bedakah disajikan pada Tabel 3.

Tabel 3. Kapasitas pemetik di Kebun Bedakah bulan Januari-April 2018

\begin{tabular}{|c|c|c|c|c|c|}
\hline \multirow[t]{2}{*}{ Blok } & \multicolumn{3}{|c|}{$\left(\mathrm{kg}\right.$ orang $\left.^{-1}\right)$} & \multicolumn{2}{|r|}{ Rata-rata } \\
\hline & Januari & Februari & Maret & April & \\
\hline Bismo & 94.50 & 93.93 & 76.61 & 99.60 & 91.16 \\
\hline Rinjani & 108.66 & 94.87 & 72.79 & 87.24 & 90.89 \\
\hline Argopuro & 110.77 & 96.25 & 87.79 & 115.98 & 102.70 \\
\hline Mandala & 137.17 & 118.70 & 112.89 & 103.07 & 117.96 \\
\hline Kembang & 107.16 & 95.06 & 95.30 & 111.02 & 102.14 \\
\hline Muria & 111.72 & 91.95 & 61.23 & 86.50 & 87.85 \\
\hline Rata-rata & 111.66 & 98.46 & 84.44 & 100.57 & 98.78 \\
\hline
\end{tabular}

Sumber : Laporan produksi Kebun Bedakah tahun 2018 
Tingkat produktivitas tenaga pemetik dapat diketahui dengan melakukan analisis terhadap 10 tenaga pemetik yang masing-masing digolongkan berdasarkan usia pemetik. Tabel 4 menunjukkan usia tenaga pemetik berpengaruh nyata terhadap kapasitas pemetik.

Tabel 4. Kapasitas Pemetik Berdasarkan Usia Pemetik di Kebun Bedakah Bulan Januari-April 2018

\begin{tabular}{ccc}
\hline Usia (tahun) & $\mathrm{n}$ (orang) & $\begin{array}{c}\text { Rata-rata Kapasitas } \\
\text { Pemetik }\left(\mathrm{kg} \mathrm{orang}^{-1}\right)\end{array}$ \\
\hline$<40$ & 10 & $70.10 \mathrm{a}$ \\
$>40$ & 10 & $44.72 \mathrm{~b}$ \\
\hline
\end{tabular}

Keterangan : Angka-angka yang diikuti huruf yang berbeda pada kolom yang sama menunjukkan nilai berbeda nyata berdasarkan uji $t$-student dengan taraf $5 \%$

Berdasarkan pengamatan masih banyak pemetik berusia diatas 40 tahun. Bertambahnya usia menyebabkan kemampuan pemetik dalam memetik teh berkurang. Topografi kebun juga menjadi kendala bagi pemetik berusia lanjut dalam melaksanakan kegiatan pemetikan. Kapasitas pemetik di Kebun Bedakah lebih sering dipengaruhi oleh keadaan pucuk di lapang, topografi kebun, cuaca, keterampilan pemetik, populasi tanaman pada blok yang akan dipetik, dan umur pangkas. Kondisi kebun sangat mempengaruhi tingkat produksi yang akan dihasilkan. Kondisi kebun yang sehat akan menghasilkan produksi yang maksimal sehingga dapat meningkatkan kapasitas pemetik.

\section{Kebutuhan Tenaga Pemetik}

Tenaga pemetik merupakan salah satu faktor yang harus di perhatikan agar dapat memperoleh hasil petikan yang maksimal.
Produksi maksimal dapat dicapai jika ketersediaan tenaga kerja sesuai dengan rasio kebutuhan tenaga kerja. Jumlah tenaga petik di Kebun Bedakah yaitu 204 orang. Berdasarkan rasio tenaga pemetik maka masih dibutuhkan sebanyak 10 orang untuk memenuhi kebutuhan tenaga pemetik sebanyak 214 orang. Jumlah tenaga pemetik dan rasio tenaga pemetik di Kebun Bedakah disajikan pada Tabel 5.

Pada Tabel 5 dapat dilihat kebutuhan tenaga kerja dengan penyebaran tenaga pemetik yang tidak merata. Hal ini tidak mudah melakukan penyebaran dikarenakan pengaruh tempat tinggal yang berdekatan dengan kebun dan sulit mendapatkan tenaga pemetik baru dikarenakan kurang peminat dari masyarakat dengan usia produktif untuk bekerja sebagai pemetik. Faktor yang dapat menyebabkan kurangnya peminat yaitu dikarenakan upah yang minim sehingga masyarakat lebih memilih untuk bekerja sebagai petani. Kurangnya jumlah tenaga pemetik dapat menyebabkan target tidak dapat tercapai karena hanca petik yang telah ditetapkan tidak dapat terselesaikan sehingga memperpanjang gilir petik yang telah direncanakan.

\section{Produktivitas Berdasarkan Umur Setelah Pangkas}

Produktivitas tanaman teh akan sebanding dengan bertambahnya umur pangkas. Semakin tua umur pangkasan maka akan semakin banyak bagian tanaman yang membutuhkan hasil fotosintesis sehingga pucuk yang dihasilkan berukuran lebih kecil dan lebih ringan meskipun jumlah pucuk semakin banyak (Tobroni, 1988). Produksi atau produktivitas tanaman sangat dipengaruhi oleh kesehatan tanaman itu sendiri.

Tabel 5. Kebutuhan Tenaga Pemetik dan Rasio Tenaga Pemetik di Kebun Bedakah Tahun 2018

\begin{tabular}{lccccc}
\hline \multicolumn{1}{c}{ Blok } & $\begin{array}{c}\text { Target } \\
\text { Produksi } \\
\left(\mathrm{kg} \mathrm{tahun}^{-1}\right)\end{array}$ & $\begin{array}{c}\text { Luas } \\
\text { Areal TM } \\
(\mathrm{ha})\end{array}$ & $\begin{array}{c}\text { Rasio Tenaga } \\
\text { Pemetik } \\
\left(\text { orang ha }^{-1}\right)\end{array}$ & $\begin{array}{c}\text { Tenaga } \\
\text { Kerja Riil } \\
(\text { orang })\end{array}$ & $\begin{array}{c}\text { Kebutuhan } \\
\text { Tenaga } \\
\text { Kerja (orang) }\end{array}$ \\
\hline Bismo & 921000 & 60.86 & 0.69 & 46 & 42 \\
Rinjani & 598000 & 41.81 & 0.66 & 22 & 28 \\
Argopuro & 874000 & 60.04 & 0.67 & 29 & 40 \\
Mandala & 864000 & 56.71 & 0.70 & 26 & 40 \\
Kembang & 587000 & 42.64 & 0.63 & 46 & 27 \\
Muria & 807000 & 53.64 & 0.69 & 204 & 37 \\
\hline Jumlah & 4651000 & 315.70 & 4.04 & 34 & 214 \\
\hline Rata-rata & & 52.62 & 0.67 & 36 \\
\hline Sumber & & &
\end{tabular}

Sumber : Laporan Produksi Kebun Bedakah tahun 2018 dan hasil pengamatan 
Kondisi pucuk yang baik dapat dilihat juga dari pertumbuhan pucuk yang seragam serta merata pada semua perdu tanaman. Produksi yang meningkat akan diikuti pula oleh peningkatan produktivitas.

\section{KESIMPULAN}

Pengelolaan pemetikan pada Kebun Bedakah belum memenuhi standar yang telah ditetapkan, Mutu teh pada Kebun Bedakah juga belum memenuhi standar yang telah ditetapkan. Analisis petik pada bulan Mei 2018 dengan komposisi pucuk medium sebesar $23.83 \%$ belum memenuhi standar yang ditetapkan yaitu $50 \%$. Analisis pucuk pada bulan Januari-April 2018 dengan rata-rata sebesar $48.78 \%$ pucuk memenuhi syarat pengolahan (MS) belum memenuhi standar yaitu 50\%. Gilir petik di Kebun Bedakah yaitu berkisar 49-73 hari. Hanca per pemetik di Kebun Bedakah adalah 0.031 ha $\mathrm{HK}^{-1}$. Jumlah tenaga pemetik yang dimiliki yaitu 204 orang, jumlah tersebut masih kurang dari rasio tenaga pemetik yaitu 214 orang. Kapasitas pemetik Kebun Bedakah sebesar $98.78 \mathrm{~kg}$ per pemetik belum memenuhi standar yang ditetapkan yaitu sebesar $100 \mathrm{~kg}$ per pemetik per hari. Kapasitas pemetik dipengaruhi oleh usia pemetik.

\section{DAFTAR PUSTAKA}

Ditjenbun. 2015. Statistik Perkebunan Indonesia 2014-2016: Teh. Sekretariat Direktorat Jendral Perkebunan, Jakarta.

[ITC] International Tea Committee. 2015. Annual Bulletin of Statistics 2015. International Trade Center.
Kementerian Pertanian. 2014. Perkembangan Pasar Teh Indonesia di Pasar Domestik dan Pasar Internasional Tahun 2014. Balai Penelitian Tanaman Industri dan Penyegar Kementerian Pertanian, Jakarta.

Qibtiyah, M. 2009. Pengelolaan pemetikan tanaman teh (Camellia sinensis (L.) O. Kuntze) di Unit Perkebunan Tambi, PT Tambi, Wonosobo, Jawa Tengah. [Skripsi]. Institut Pertanian Bogor, Bogor.

Setyamidjaja, D. 2000. Budidaya dan Pengolahan Pasca Panen Tanaman Teh. Kanisius, Yogyakarta.

Supit, A. 2009. Keuangan pasokan teh dunia berkurang. http://www.ptpn7.com [7 Maret 2016].

[PPTK Gambung] Pusat Penelitian Teh dan Kina. 2006. Implementasi teknologi untuk mencapai industri teh berkelanjutan. Dalam: Pusat Penelitian Teh dan Kina Gambung $(E d)$. Prosiding Pertemuan Teknis 40 Industri Teh Berkelanjutan; Agro Gunung Mas PTPN VIII Bogor, 12-13 September 2006.

[PPTK Gambung] Pusat Penelitian Teh dan Kina. 2010. Standar Operasi Prosedur Pemetikan. Pusat Penelitian Teh dan Kina Gambung, Bandung

Tobroni. 1988. Pangkasan pada Tanaman Teh Muda. Prosiding Seminar Pemangkasan Teh. Balai Penelitian Teh dan Kina Gambung, Bandung. 